\title{
TRABALHO DOCENTE VOLUNTÁRIO EM UMA UNIVERSIDADE FEDERAL: NOVA MODALIDADE DE TRABALHO PRECARIZADO?
}

\author{
Valeska Nahas Guimarães* \\ Sandro Vieira Soares** \\ Maria Denize Henrique Casagrande ${ }^{* * *}$
}

RESUMO: Este artigo apresenta os resultados de uma pesquisa que tem como principal objetivo realizar um estudo reflexivo sobre o trabalho docente voluntário em uma Instituição de Ensino Superior e sua regulamentação interna. A pesquisa é qualitativa e foi desenvolvida de acordo com uma perspectiva crítica de análise. Foram aplicados questionários com professores voluntários e realizado um levantamento documental. A relevância do estudo reside no fato de desvelar a situação do trabalho docente voluntário em uma Universidade Pública, cujas conclusões não são consensuais, bem como, realizar uma avaliação da legislação vigente, confirmando-se a hipótese de que a Instituição Federal de Ensino Superior pesquisada não possui uma política interna nem programas específicos relacionados ao trabalho docente voluntário. As conclusões remetem também à questão da flexibilização e precarização do trabalho docente.

Palavras-chave: Trabalho Docente Voluntário; Instituições de Ensino Superior; Condições de Trabalho.

\section{VOLUNTARY TEACHING IN A FEDERAL UNIVERSITY: A NEW MODE OF PRECARIOUS WORK?}

ABSTRACT: This article presents the results of a survey which main objective was to conduct a reflective study on teachers' voluntary work at a High Education Institution and its internal regulations. It is a qualitative research developed according to critical analysis. Questionnaires were applied to volunteer teachers and a documentary survey was carried out. The relevance of the study lies on the fact of revealing the status of volunteer teaching in a public university, whose conclusions are not consensual, as well as performing an evaluation of the current legislation, confirming the hypothesis that the Federal Institution of Higher Education surveyed lacks an internal policy or specific programs regarding volunteer teaching. The conclusions also refer to the issue of flexibility and precariousness of teaching.

Keywords: Volunteer Teaching; Higher Education Institutions; Labor Conditions.

\footnotetext{
*Doutora em Engenharia de Produção pela Universidade Federal de Santa Catarina (UFSC); Professora do Programa de Pós-Graduação em Educação da Universidade Federal de Santa Catarina (UFSC) e Pesquisadora do Núcleo Interdisciplinar de Estudos da Inovação e do Trabalho (NINEIT) da Universidade Federal de Santa Catarina (UFSC). E-mail: valeska_kenaz@yahoo.com.br

* *Acadêmico do Curso de Ciências Contábeis da Universidade Federal de Santa Catarina (UFSC); Bolsista Voluntário de Iniciação Científica no Departamento de Ciências Contábeis da Universidade Federal de Santa Catarina (UFSC). E-mail: sandrovieirasoares@hotmail.com

*** Doutora em Engenharia de Produção pela Universidade Federal de Santa Catarina (UFSC); Professora do Departamento de Ciências Contábeis da Universidade Federal de Santa Catarina (UFSC); Pesquisadora do Núcleo Interdisciplinar de Estudos da Inovação e do Trabalho (NINEIT) da Universidade Federal de Santa Catarina (UFSC) e do Núcleo de Estudos sobre Meio Ambiente e Contabilidade (NEMAC) da Universidade Federal de Santa Catarina (UFSC). E-mail: denize@cse.ufsc.br
} 


\section{INTRODUC̣ÃO}

Este artigo apresenta os resultados de uma pesquisa exploratóriodescritiva que tem como principal objetivo realizar um estudo reflexivo sobre o trabalho docente voluntário em uma Instituição de Ensino Superior - IES e a regulamentação interna dessa atividade. $\mathrm{O}$ interesse por este tipo de estudo decorre da vivência de uma das pesquisadoras neste tipo de atividade, desde a sua aposentadoria, em abril de 2003.

A ausência de pesquisas avaliativas anteriores em outras universidades ${ }^{1}$, bem como a escassez de estudos e de publicações relacionadas à temática específica do trabalho docente voluntário em universidades públicas, destaca a relevância de tal estudo que visa, num primeiro momento, refletir sobre a situação atual do trabalho docente voluntário na IES e a legislação interna que o regulamenta, para, numa etapa posterior, realizar estudos comparativos interuniversidades e apresentar propostas de políticas e programas específicos relacionados à questão.

Observamos que os estudos apontados na literatura sobre as transformações do trabalho docente nas Instituições de Ensino Superior (IES) no Brasil ainda não são numerosos, conforme destaca Bosi (2007, p. 2) e, "geralmente, atêm-se à dimensão da flexibilização das relações contratuais de trabalho". Dentre as pesquisas levantadas encontram-se as de Oliveira (1996); Pinto (2000); Pinto (2002); Dal Rosso (2001); Inácio e Wagner (2003). Estas pesquisas vêm discutindo, pouco ou quase nada, acerca das transformações experimentadas na rotina do trabalho acadêmico (ensino, pesquisa e extensão). Bosi (2007) adverte que, mesmo no caso de outros países da América Latina, a tendência tem sido a de considerar a precarização do trabalho docente nas universidades apenas como "flexibilização dos direitos e contratos trabalhistas".

Por essa razão, consideramos premente um estudo que procure desvelar a situação do trabalho docente voluntário numa Universidade Pública, um tema controverso e polêmico. A pesquisa é importante, também, porque objetiva apresentar um panorama da situação e das condições de trabalho dos docentes voluntários, relacionando-as às 'novas formas' de gestão que enaltecem a flexibilização do trabalho em um contexto de 'enxugamento' dos quadros de pessoal do serviço público, especificamente o das Instituições Federais de Ensino Superior - IFES. 
Nesse sentido, o presente artigo apresenta os resultados da primeira etapa da referida pesquisa, quando buscamos as avaliações pessoais de professores voluntários sobre as suas motivações, as expectativas e as condições e relações de trabalho na vivência do voluntariado, bem como a avaliação da legislação interna vigente.

\section{TRABALHO VOLUNTÁRIO: CONCEITOS, SIGNIFICADO PESSOAL E SOCIAL, MARCO LEGAL}

A interpretação de trabalho, associado no capitalismo à venda da força de trabalho pelo trabalhador ao capitalista, nas últimas décadas vêm sendo amplamente discutida, em função das novas configurações do mundo do trabalho, especificamente em um período caracterizado por intensas transformações sociais, econômicas e produtivas. Dessa forma, a identificação de trabalho com emprego não é mais aceitável, considerando-se o emprego como a formalização legal do trabalho, com os direitos sociais assegurados ao trabalhador pela legislação pertinente, vigente em cada país. Atualmente, com a crescente flexibilização do trabalho, cada vez menos trabalhadores são contratados com vínculo formal - carteira de trabalho assinada. A flexibilização, na maioria dos casos, reflete uma estratégia de mascaramento das relações de trabalho e uma forma atuante de intensificação da exploração do trabalhador.

Nesse aspecto, observa-se que a precarização do trabalho, historicamente uma característica do trabalho no capitalismo, está fortemente associada com a flexibilização das relações de trabalho. No entanto, deve-se ter em conta a advertência de Alves (2005, p. 6) para o fato de que a “[...] precarização do trabalho possui uma particularidade socioeconômica diferenciada da precarização (e precariedade) de outras épocas históricas do capital [...]". No entendimento de Alves (2005, p. 6), o que observamos hoje no mundo do trabalho não é uma regressão histórica conjuntural a uma situação socioinstitucional dos primórdios do capitalismo. Ao invés de ser uma mera "patologia social", a precarização do trabalho é a forma de ser da normalidade sistêmica do capital em sua etapa de crise estrutural. ${ }^{2}$

Assim, novas formas de trabalho precarizado fazem-se presentes por meio da utilização de estagiários, trabalhadores temporários, de cooperativas de trabalho e/ou associações de produção, bem como, do 
trabalho voluntário, apologeticamente apresentado na mídia como uma "alavanca ao desenvolvimento do país", e o voluntário como um agente de transformação social, especificamente tratando-se da área de atuação na educação ou idilicamente representado como "amigo da escola".

Nesse sentido, há um entendimento crítico sobre determinados tipos de trabalho voluntário que servem ao descumprimento das funções básicas do Estado em áreas prioritárias, como educação e saúde, transferindo-se atividades que requerem a presença de profissionais capacitados, com vínculo permanente, para trabalhadores voluntários que podem ou não ser igualmente capacitados para as mesmas funções. Dessa forma, observa-se que a interpretação de trabalho voluntário é bastante polêmica, sendo que a sua concepção e valoração sofreram modificações ao longo da história.

Inicialmente era identificado somente como assistencialismo, filantropia ou caridade, com conotação essencialmente religiosa. Atualmente, esse tipo de trabalho filantrópico é reconhecido como "trabalho voluntário", "serviço comunitário" e/ou ações de "responsabilidade social", observando-se uma passagem temporal e histórica de prática filantrópica a um processo de profissionalização ${ }^{3}$, o que caracteriza uma reformulação das suas bases conceituais, assentadas nos princípios morais e religiosos da caridade, fraternidade e do assistencialismo para uma proposta "investimento em ação social".

Assim, instaura-se concretamente uma contradição, tratando-se do trabalho voluntário, socialmente útil, e a sua expressão no capitalismo contemporâneo, como ações de "responsabilidade social" praticadas por agentes individuais, institucionais ou empresariais, cujas finalidades na maioria das vezes não estão claramente desveladas/reveladas (RAMPINELLI; GUIMARÃES, 2006). Ou seja, o voluntariado se afirma como um trabalho social sem finalidade lucrativa, mas essa característica é negada na medida em que o voluntariado revela-se - ao mesmo tempo - um elemento para ampliar o lucro (ainda que indiretamente), como um instrumento de marketing social para as empresas capitalistas. A reflexão sobre tal processo relaciona-se a um debate mais amplo que inclui a categoria trabalho, a sua centralidade e aplicação no capitalismo contemporâneo, que se pretende realizar no decorrer da pesquisa.

No Brasil, nas últimas décadas, constata-se o surgimento de políticas públicas, programas e ações dirigidas ao denominado terceiro setor, lócus privilegiado da aterialização do trabalho voluntário, inseridos 
no que se convencionou chamar de "outra economia" (CATTANI, 2003), "economia solidária", "economia popular", ou "economia social" (SINGER, 2003). Entretanto, ações governamentais ou privadas racionadas ao trabalho voluntário no Brasil não se restringem às últimas décadas, mas remontam aos primeiros anos da colonização, com a fundação da Santa Casa de Misericórdia de Santos, em 1543. Neste período, religião e caridade estavam fortemente concentradas na área da saúde. Em 1908, é fundada a Cruz Vermelha Brasileira, reconhecida pelo Governo como uma sociedade autônoma de socorro voluntário. Dois anos depois, surge o escotismo no Rio de Janeiro, cuja regra era "ajudar o próximo em toda e qualquer ocasião".

Dentre outras iniciativas que privilegiaram o trabalho voluntário, destacam-se (Quadro 1):

\section{Quadro 1. Marcos na história do trabalho voluntário.}

A criação da Legião Brasileira de Assistência - LBA, pela então primeira dama, Darcy Vargas, 1942, uma instituição criada com o objetivo de amparar e prestar assistência aos soldados mobilizados pela Segunda Guerra Mundial e aos seus familiares. Em 1991, a LBA por meio do Decreto $\mathrm{n}^{0} .12$ de 18 de janeiro de 1991, transformou-se na "Fundação Legião Brasileira de Assistência".

Programa Nacional do Voluntariado-PRONAV, vinculado à LBA, que vigorou de 1979 ao início dos anos 90, do século XX.

Ação da Cidadania Contra a Miséria e pela Vida, em 1993, um movimento coordenado por Herbert de Souza, o Betinho, que teve ampla repercussão nacional e despertou na sociedade civil a vontade de atuar para a resolução de problemas imediatos e 0 aumento de reivindicações junto ao governo.

Comunidade Solidária e Programa de Voluntariado, criada em 1995, no Governo Fernando Henrique Cardoso, coordenado pela primeira dama, Ruth Cardoso.

Lei do Voluntariado - Lei 9.608 de 1998 - marco legal do trabalho voluntário.

Portal do Voluntariado, criado em 1998, a partir da lei que instituiu a comunidade solidária e o programa de voluntariado, o Portal do Voluntário é um site com conteúdos, experiências e oportunidades de ação voluntária. Nesse portal, destaca-se que "o voluntariado é um ato do coração e uma virtude cívica", com um forte apelo ao exercício da cidadania e do civismo.

Instituto Voluntários em Ação, criado em 1998 em Santa Catarina.

Ano do Voluntariado (2001) - declarado pela Organização das Nações Unidas, ONU, quando se observou mundialmente uma proliferação de ações, investimentos, divulgação na mídia, realização de simpósios, encontros, seminários, visando sensibilizar as empresas e os cidadãos para 0 trabalho voluntário, promovendo adesões e capacitação para esta finalidade. 
Porém, para que se efetivem todas essas ações relacionadas ao trabalho voluntário, é necessária a existência de uma legislação. No Brasil, o trabalho voluntário passou a ser regido pela Lei no 9.608, de 18 de fevereiro de 1998, que estabelece em seu artigo primeiro:

Considera-se serviço voluntário, para fins desta Lei, a atividade não remunerada, prestada por pessoa física a entidade pública de qualquer natureza, ou a instituição privada de fins não lucrativos, que tenha objetivos cívicos, culturais, educacionais, científicos, recreativos ou de assistência social, inclusive mutualidade.

Parágrafo único. O serviço voluntário não gera vínculo empregatício, nem obrigação de natureza trabalhista previdenciária ou afim. (BRASIL, 1998)

No seu artigo $2^{\circ}$, a lei determina que o trabalho voluntário seja exercido mediante a celebração de termo de adesão entre a entidade receptora (pública ou privada), devendo constar o objeto e as condições de exercício. Também destaca a pertinência de ressarcimento de despesas comprovadas, no exercício das atividades voluntárias. No caso das instituições públicas como as Universidades Federais, fica a critério de cada uma regulamentar o trabalho voluntário, respeitando a Lei 9.608/98.

$\mathrm{Na}$ IES em estudo, o trabalho voluntário é regulamentado pela Resolução no 012/1999 aprovada pelo Conselho Universitário (UNIVERSIDADE FEDERAL DE SANTA CATARINA, 1999). O interessado em desenvolver atividades voluntárias de ensino, pesquisa e extensão na IES deve dar entrada a um processo que tramitará pelas seguintes instâncias: Colegiado da Pós-Graduação, Colegiado do Departamento, Conselho Departamental do Centro e, finalmente, Gabinete do Reitor, no qual este assinará, juntamente com o solicitante, um termo de adesão com vigência de dois anos, prorrogáveis a cada dois anos. A qualquer momento, por iniciativa em uma das partes (docente ou reitor) poderá ser solicitada a assinatura de um termo de "distrato". Um procedimento burocrático adicional deverá ser seguido de acordo com a Resolução 012/99.

\section{METODOLOGIA DA PESQUISA}

A pesquisa realizada é exploratório-descritiva com abordagem qualitativa. Porém, tratando-se dos métodos e técnicas privilegiamos tanto os 
métodos qualitativos quanto os quantitativos de levantamento e tratamento das informações, pois utilizamos o método quantitativo de tabulação pelo software $\mathrm{Excel}^{\circledR}$, procedendo-se concomitantemente a uma análise qualitativa com a inclusão de falas sugestivas dos professores.

O levantamento de dados e informações iniciou-se com uma pesquisa acerca do tema em sites de pesquisa, tais como: Portal da Capes, Banco de Teses e Dissertações de diversas universidades, Instituto Brasileiro de Informação em Ciência e Tecnologia, dentre outros. Para iniciarmos o estudo sobre o trabalho voluntário na IES, realizamos um estudo piloto com um grupo de sete professores aposentados voluntários no primeiro semestre de 2007, quando debatemos o tema do trabalho voluntário e aplicamos entrevistas informais. Este estudo piloto proporcionou aos pesquisadores uma aproximação com o tema da pesquisa e a elaboração do instrumento de pesquisa, um questionário com 18 perguntas fechadas e abertas.

A seguir levantamos junto ao gabinete do reitor informações relativas aos professores que assinaram o termo de adesão entre 2005 e 2007, cumprindo a exigência da Resolução 012/99. Estas informações foram complementadas mediante levantamentos nos sites de Departamentos de Ensino e Programas de Pós-graduação (pesquisa telematizada, segundo Vergara (2002)), além de contatos telefônicos e pessoais, possibilitando um mapeamento situacional mais completo. No caso do Centro de Ciências da Saúde, em função das suas peculiaridades, tornou-se necessário o levantamento in loco, pois inclui a atuação de voluntários nas clínicas de odontologia e do Hospital Universitário. Por meio destes levantamentos, evidenciou-se uma condição não prevista: a participação de voluntários não aposentados na docência.

A partir da relação de professores voluntários, complementada e atualizada, na qual foram incluídos professores que assinaram o termo de adesão ou não, aposentados ou não, encaminhamos 66 questionários, retornando 22, número considerado satisfatório e representativo de centros de ensino, departamentos e programas de pós-graduação bem como da diversidade de situações (professores aposentados e não aposentados; ensino de pós-graduação e graduação; atividades no ensino, pesquisa e/ou extensão). A identidade dos professores foi preservada. 


\section{QUEM É O PROFESSOR VOLUNTÁRIO DA IES ESTUDADA?}

De acordo com a amostra obtida, a distribuição dos professores voluntários por centros de ensino demonstra uma pequena predominância do Centro Tecnológico (CTC), com 20\% dos entrevistados (quatro), seguido pelo Centro de Educação (CED), Centro de Filosofia e Ciências Humanas (CFH) e o Centro de Ciências da Saúde (CCS) com 15\% (três) professores cada um. Estes quatro Centros responderam por mais da metade, (65\%) dos entrevistados. O retorno é compatível com a relação fornecida pelo gabinete do reitor, em que se observa a predominância de professores voluntários no CTC. Os Centros de Comunicação e Expressão (CCE), Centro de Ciências Físicas e Matemáticas (CFM) e Centro de Ciências Biológicas (CCB) tiveram 10\% cada um (dois professores) e Centro Sócio-Econômico (CSE) apenas 5\% (um professor), dados também compatíveis com a relação oficial.

Entre os entrevistados, a proporção de indivíduos que afirmaram serem pesquisadores do $\mathrm{CNPq}$ foi de $35 \%$ (sete), sendo que havia uma expectativa de que esse número fosse maior. Cerca de 65\% (13) participa de grupos de pesquisa e, destes, 8 são líderes do grupo. Quanto à assinatura do termo de adesão de voluntário, $85 \%$ (dezessete) assinaram o referido termo. Constatamos que as motivações destacadas em relação à assinatura do termo de adesão, de modo geral, são de caráter legalista: "a condição de regularização", "a necessidade de vínculo institucional" e o "interesse em participar de grupo de pesquisa”. Apenas um voluntário ressaltou a questão da "obrigatoriedade".

Dos docentes voluntários que responderam ao questionário, 70\% (14) são aposentados. Porém, nesse aspecto, a expectativa dos pesquisadores era de encontrar somente professores aposentados no trabalho docente voluntário e com termo de adesão assinado ${ }^{4}$. A idade média dos professores aposentados é de 62 anos com valor modal de 58 anos. A idade média dos voluntários não aposentados é de 34 anos e o valor modal é de 39 anos.

Quanto à data de aposentadoria dos 14 docentes voluntários aposentados, observamos maior concentração entre 2003-2006 (nove docentes) representativa da situação geral da IES, quando um número muito expressivo de docentes decidiu pela aposentadoria, em parte, decorrente de novas regulamentações em curso.

As atividades atuais na universidade que estes docentes exercem incluem, em grande parte dos casos, o ensino e a pesquisa concomitantemente 
(35\%). Mas há casos em que o voluntário desenvolve somente atividades de ensino $(10 \%)$ ou somente pesquisa $(15 \%)$ e os demais $(40 \%)$ desenvolvem um mix de atividades de pesquisa e extensão; ensino e extensão; ensino, pesquisa e extensão. Porém, nenhum dos voluntários docentes entrevistados executa apenas atividades de extensão.

Em relação aos Programas de Pós-Graduação, aos quais estão vinculados, houve uma ampla distribuição com uma leve concentração no Programa de Pós-graduação de Educação (15\%, ou seja, três professores). A dispersão dos respondentes em 15 Programas revela uma amostra bastante eclética abrangendo: Ciências da Computação e Sociologia Política (dois professores em cada uma); Física, Clínica Integrada, Biotecnologia, Química, Letras, Engenharia de Produção, Educação Científica e Tecnológica, Jornalismo, Geografia, Patologia Experimental, Serviço Social e Engenharia Química (um professor em cada programa). Apenas um voluntário não estava vinculado a nenhum programa de pós-graduação.

A maioria (65\%) dos entrevistados não possui vínculo com cursos de graduação; os cursos que apresentaram voluntários no ensino de graduação são: Medicina, Física, Odontologia, Ciências Sociais, Engenharia Química e Engenharia de Alimentos. A não vinculação com cursos de graduação era uma expectativa dos pesquisadores, tendo em vista as entrevistas informais e contatos anteriores com professores voluntários que demonstram maior interesse em continuar seu trabalho somente na pós-graduação e na pesquisa.

Tratando-se de orientações no doutorado, a maioria dos entrevistados tem orientandos $(65 \%)$, predominando a orientação de até três doutorandos (55\% dos casos). Quanto às orientações no mestrado, $45 \%$ dos voluntários não orientam nenhum aluno; 45\% orientam de um a três mestrandos, e apenas um professor $(5 \%)$ orienta mais de três mestrandos. A maioria dos entrevistados (70\%) afirmou não orientar nenhum graduando, o que é compatível com o fato da não participação da maioria dos voluntários (65\%) nos cursos de graduação.

Constatamos que os voluntários não se dedicam exclusivamente ao trabalho na IES, pois $60 \%$ dos entrevistados (12) exercem atividades profissionais externas, sendo que, em apenas um caso, a atividade exercida não é remunerada. Estas atividades profissionais externas concentram-se na docência em outras universidades (34\%), atendimento em consultório médico particular $(25 \%)$ e consultoria $(25 \%)$. 


\section{AVALIAÇÃO DA LEI DO VOLUNTARIADO E DA LEGISLAC̣ÃO INTERNA DA IES EM QUESTÃ̃ $0^{5}$}

O conhecimento da legislação brasileira referente ao trabalho voluntário é de 'desconhecimento geral' da maioria dos entrevistados $(85 \%$, 17 professores). Só um entrevistado respondeu que conhece a legislação e apenas dois que conhecem "um pouco". Este fato demonstra que não há uma preparação prévia para o trabalho voluntário, no que tange aos aspectos legais, tanto por parte da IES quanto dos interessados. Um dos entrevistados que disse conhecer a legislação federal que regulamenta o trabalho voluntário, professor aposentado compulsoriamente, tece críticas à Lei 9.608/98, evidenciando o lado 'torpe' de exploração do trabalho qualificado:

(01) Li a Lei n 9.608/98. Fica evidente que, ao longo dos seus cinco artigos, verifica-se que o legislador se preocupon, basicamente, em distingui-lo do trabalho assalariado. Considero-a uma maneira injusta, imoral e autoritária de explorar de graça o trabalho (em nosso caso, valioso) de funcionários experientes, colocando-os diante de uma escolha difícil: começar algo novo em idade avançada ou prestar-se ao trabalho gratuito, num ocaso sem glórias [...] (Ent. 14, CCE, grifo nosso).

Por outro lado, tratando-se da legislação interna da IES que regulamenta o trabalho voluntário, constatamos que 70\% dos entrevistados "afirmam que a conhecem". Esta diferença entre o conhecimento da legislação brasileira e a legislação interna da IES pode ser explicada pelo fato de que, na ocasião da assinatura do termo de voluntário, os entrevistados são informados acerca da legislação interna. As críticas à Resolução 012 inicia-se a partir da denominação "professor voluntário", considerando o entendimento geral que se tem deste tipo de trabalho, associado a uma não profissionalização ou não competência. Dessa forma, os professores assim se manifestaram: "gostaria que fosse mudada a denominação de 'professor voluntário' para uma formulação mais pertinente a um trabalho que conta com maior experiência" (Ent. 1, CED), ou mesmo, que "poderia ser algo como professor emérito ou semelhante” (Ent. 5, CFM).

Destaque para a avaliação comparativa com outras instituições contida na fala do "Penso que um grande aspecto negativo é o próprio nome - professor voluntário -, quando, em outras universidades, os 
professores que retornam para colaborar com a Universidade têm sido colaborador sênior" (Ent. 8, CSE, grifo nosso).

Nesse aspecto, uma professora voluntária do Centro Tecnológico, no qual a existência de professores voluntários é vista com certo 'espanto', manifestou-se, ironizando sobre a denominação "voluntário":

(02) Lembro que na ocasião [da assinatura do termo de adesão] fiquei com a impressão que a UFSC estaria fazendo um favor para mim, me permitindo ficar como voluntária (ou vol-otária, como brincam alguns colegas) [...] (Ent. 10, CTC, grifo nosso).

O fato da Resolução 012 exigir um coorientador para os trabalhos orientados pelo professor voluntário foi destacado como um aspecto negativo pelos entrevistados. A fala a seguir é elucidativa e crítica:

(03) Aspecto negativo: a exigência de um coorientador nas orientações do professor voluntário. Se ele orientou por anos e anos, por que essa exigência? Também para que "supervisor" (formal ou informal) se o professor tem um programa de trabalho e vai apresentar relatório? Aspecto positivo: é aberta, permitindo flexibilidade, mas, o que é importante, exige a apresentação do programa de trabalho [...] (Ent. 15, CFH).

Por sua vez, um professor voluntário, que começou como professor visitante, evidencia um aspecto pouco destacado: a falta de reconhecimento institucional pelo seu trabalho, o que interfere diretamente na motivação para o exercício deste tipo de trabalho:

(04) Algo que sempre senti muita falta aqui, desde a época de Pesquisador Visitante, refere-se ao reconhecimento da Instituição de que existo para ela e aqui desenvolvo atividades semelhantes àquelas exercidas pelos Professores do quadro docente da Instituição. Isto não quer dizer que a grande maioria dos colegas de Departamento tenha qualquer restrição à minha atuação por aqui, mas a Universidade em si não demonstra reconhecimento formal de minha presença na Instituição (Ent. 18, CTC, grifo nosso).

Uma avaliação mais crítica foi apresentada por um professor aposentado, alertando para o fato de que esta resolução tem um propósito, um claro objetivo, qual seja: "ela põe em execução o mando escravagista, zelando para que as vítimas do esbulho jamais reclamem algum direito" (Ent. 14, CCE), avaliação esta que vai ao encontro de uma literatura crítica sobre o 
tema do voluntariado (PINTO; GUEDES; BARROS, 2006; RAMPINELLI, GUIMARÃES, 2006; TEODÓSIO; PENA; VENEROSO, 2006).

A discordância contra a obrigatoriedade de um supervisor foi observada em várias avaliações, como evidenciam as declarações seguintes, pelo fato de ser uma cobrança injustificada sobre um profissional experiente e responsável:

(05) [...] não seria necessário um professor "supervisor" tendo em vista que os aposentados normalmente são doutores e com larga experiência. Se não cumprem o contrato é a mesma situação de quando professores interrompem as atividades - seja por afastamento questão saúde ou outro motivo [...] (Ent. 8, CSE).

(06) Conheço a Resolução 012. Não gosto da parte relativa ao supervisor, ainda que não tenha nenhum problema com o meu. Acho que é desnecessário para aposentados da própria UFSC, que já são conhecidos pelos seus pares (Ent. 4, CFM).

Os aspectos positivos apontados por três entrevistados sobre a legislação interna da IES referem-se à permissão da continuidade de um trabalho anteriormente iniciado e a formalização do trabalho voluntário no âmbito da universidade. A desproporcionalidade entre os aspectos positivos e negativos é um indício de insatisfação por parte dos voluntários no que tange à regulamentação interna do trabalho voluntário.

\section{OS MOTIVOS PELA OPC̣ÃO DO “TRABALHO VOLUNTÁRIO"}

Pelos depoimentos apresentados, observamos que o fator motivacional acaba por se tornar mais forte do que as limitações associadas à regulamentação interna, pois, em suas respostas, os professores destacam que a opção pessoal pelo trabalho voluntário deu-se principalmente pelo "interesse em continuar atuando na universidade em melhores condições", "o interesse em continuar pesquisando", "o prazer pelo trabalho/ não querer parar de trabalhar" e "o apreço pela Instituição".

Permanecer como docente e ter a vantagem da redução da jornada de trabalho são motivos da opção como docente voluntário e aparecem destacados em duas falas: "aposentei-me para reduzir a jornada de trabalho. Gosto do trabalho na UFSC, apenas queria trabalhar de forma menos intensa” (Ent. 6, CFM); “eu não queria parar de trabalhar, só não suportava 
mais a carga total de trabalho: graduação, mestrado, doutorado, $\mathrm{CNPq}$ etc.” (Ent. 15, CFM). A intensidade e a precarização do trabalho docente na atualidade ficam evidenciados nessas avaliações, corroborando estudos de Bosi (2007), Oliveira (1996) e Pinto (2002).

Outra questão que ficou destacada pelos entrevistados é a centralidade que o trabalho ocupa na vida dos professores, a despeito da polêmica sobre "a perda da centralidade do trabalho na sociedade contemporânea" (ANTUNES, 2004). Os depoimentos destacados a seguir são enfáticos, nesse sentido:

(07) Nunca pensei em parar de trabalhar. Acho que sou dependente emocional do meu trabalho. Também penso que é relevante para o Brasil, já que, se parar, serão menos doutores formados num momento que o Brasil precisa muito deles por causa da expansão do ensino superior [...] (Ent. 10, CTC, grifo nosso).

Esta mesma professora ressalta o motivo da aposentadoria relacionado a problemas de saúde, o que se observa em relatos de muitos professores, particularmente agravados pela sobrecarga de trabalho e intensa cobrança de produtividade, conforme destacam estudos anteriores (SGUISSARDI; SILVA JÚNIOR, 2009; BIANCHET'TI, 2006; BOSI, 2007; PINTO, 2002; DAL ROSSO, 2001; OLIVEIRA, 1996). Manifesta também uma preocupação pessoal de não prejudicar quem se inicia na carreira docente:

(08) Quando me aposentei, o fiz porque fiquei doente e eu tinha uma grande sobrecarga de trabalho [...]. Além disso, tenho a consciência tranquila em saber que não estou tirando o lugar de um jovem que está começando a carreira [...] (Ent. 10, CTC, grifo nosso).

A avaliação acima corrobora com a preocupação de Leda (2006, p. 13) quando denuncia as condições de trabalho e da educação na economia capitalista flexível, pois, segundo a autora, “[...] o docente não escapa a essa conjuntura [...] questões do seu cotidiano, certamente, geradoras de um desconforto que vai desencadeando adoecimento psíquico e somático, conforme as circunstâncias a serem vividas.” Intensificação, precarização estranhamento e desumanização nas relações de trabalho (MANCEBO; GOULART; DIAS, 2010; SILVA; SILVA JUNIOR, 2010) passam a fazer parte da literatura crítica e do cotidiano dos professores universitários, 
mesmo aqueles das instituições públicas e que denunciam a situação atual do trabalho docente no ensino superior público do País.

Mas, o desafio maior de dar continuidade ao trabalho docente a despeito da idade, superando todos os obstáculos, transparece no depoimento de dois professores aposentados compulsoriamente:

(09) Fui aposentado em forma compulsória por uma legislação obsoleta que supõe que aos $\mathbf{7 0}$ anos um professor deve deixar de pensar e produzir. Continuo com minha sala, laboratório de pesquisa, alunos e publicacooes. Acho que meu trabalho é importante para a pós-graduação, a universidade e o país [...] (Ent. 12, CTC, grifos nossos).

(10) Viver uma etapa de transição entre a rotina anterior - um círculo virtuoso, diria um economista - e algo inesperado: o retorno à situação que tive antes de começar a trabalhar, nos meus 14 anos. Um tanto de insegurança, talvez (Ent. 14, CCE, grifo nosso).

Um fato que reforça que a opção pelo trabalho voluntário na IES não ocorreu por 'falta de outra opção de trabalho', como poderia ser alegado, é a confirmação de que 12 professores voluntários (60\%) receberam convites de outras universidades para trabalhar, dentre estes, três foram convidados por mais de uma instituição. Entre as Universidades que efetuaram convites estão as Universidades Federais do Paraná e do Rio Grande do Norte; as Universidades do Sul de Santa Catarina - UNISUL, do Vale do Itajaí - UNIVALI, do Oeste de Santa Catarina - UNOESC; a Universidade Estadual de Londrina - UEL e a Católica de Pelotas - UCPEL. Duas renomadas instituições estrangeiras: a Universidade La Coruña, da Espanha e a Universidade de Kyusho, do Japão, enviaram convite a dois professores pesquisadores.

Também, no âmbito interno da IES, no que se refere aos programas de pós-graduação, a metade dos professores recebeu algum tipo de convite (da coordenação, dos professores, de ambos). E no caso dos professores que atuam na graduação, todos os seis receberam convite da chefia ou dos professores do departamento ${ }^{6}$.

\section{RELAC̣ÕES DE TRABALHO, QUALIDADE DE VIDA E CONDIC̣ÕES DE TRABALHO}

Questionados quanto ao relacionamento com os coordenadores de pós-graduação ou chefias de departamentos, todos os voluntários 
entrevistados responderam que as relações pessoais e de trabalho são boas, mas não teceram maiores comentários. Da mesma forma, o relacionamento com o professor supervisor é considerado pela maioria (55\%) como um bom relacionamento. O interessante é que $45 \%$ dos entrevistados declararam não existir relação alguma, sendo que alguns voluntários nem sabem quem é o seu professor supervisor, depreendendo-se desse fato que há departamentos que apenas cumprem formalmente a Resolução 012, mas, na prática, não a observam, por considerarem irrelevantes certas exigências, como no caso do professor supervisor.

Alegando que a figura do professor-supervisor é algo pró-forma, diversos professores manifestaram suas opiniões no sentido de seu bom relacionamento com colegas e coordenação, assim expressando-se: “[...] sem problemas com colegas, chefias e coordenadores. Tratam-me com cordialidade e respeito. Sobre o meu professor supervisor, nem sei quem é, nunca tomei conhecimento.” (Ent. 3, CED, grifo nosso); “[...] é excelente. Nem sei quem é o tal supervisor. Não me discriminam. Eu, que vim de uma família de trabalhadores, é que acho meio ridículo trabalhar de graça." (Ent. 14, CCE, grifo nosso); “[...] não tenho tido problemas. Sinto-me integrada ao Curso. Também não tenho sofrido nenhum tipo de discriminação. Não lembro sequer quem é ou foi meu supervisor." (Ent. 2, CED, grifo nosso). E ainda:

(11) [...] a questão do professor supervisor ficou como algo "pró-forma", ou seja, nunca senti nenhuma supervisão. A minha relação com os colegas, assim como com a coordenação, dá-se da mesma forma e nas mesmas condições que antecederam minha aposentadoria. Apenas oferecem-me a oportunidade de frequentar ou não, a meu critério, as reuniões convocadas (Ent. 1, CED).

Ressaltando as boas relações com seus colegas de trabalho, uma entrevistada declara desconhecer a figura do supervisor: "A relação de trabalho é muito boa. Todos são muito gentis comigo. Soube por alto desse tal professor 'supervisor', mas a figura nunca apareceu e eu até me esqueci que ela existia." (Ent.10, CTC, grifo nosso).

Observamos que, em alguns casos, o professor supervisor foi orientando do professor voluntário no doutorado, o que nos leva à reflexão acerca da necessidade dessa figura institucional para os professores aposentados pela própria IES. 
Mas, se as opiniões convergiram no que diz respeito ao supervisor, no que se refere à questão do acolhimento e respeito ao professor voluntário em seu ambiente de trabalho, as reflexões não foram suficientemente esclarecedoras, pois, embora 19 entrevistados (95\%) afirmem "sentirem-se acolhidos" (dentre estes, um grupo de professores não percebe discriminação alguma) em suas falas posteriores sobre as condições de trabalho, há evidências de contradições. Como é o caso de duas professoras aposentadas que se sentem discriminadas e assim expressam seus sentimentos:

(12) Permaneço como professora colaboradora. Tenho bom e ótimo relacionamento com algumas pessoas, mas sinto-me excluída por não ter direito a ajuda para congressos, publicações, etc. Faço tudo por conta própria, inclusive arcando com os custos [...] (Ent.19, CCE, grifo nosso).

(13) [...] quando assinei o meu primeiro contrato, tive a sensação que a UFSC estava fazendo um favor para mim. Também conheço casos de voluntários que não se sentem acolbidos pelos colegas. Acho que falta uma cultura de privilegiar o conbecimento e a experiência de professores com atuação notável [...] (Ent. 10, CTC, grifo nosso).

Um entrevistado alega que muitos professores desconhecem o trabalho que ele vem desempenhando no departamento. Da mesma forma, outro professor voluntário revela a sensação de discriminação e desconforto quando necessita solicitar algo a um determinado setor da IES, pois tem a impressão de que ao pedir algo a órgãos de administração da Universidade alguém vai perguntar: "[...] escuta aqui quem é você??" Isto aconteceu comigo [...]”, (Ent. 18, CTC, grifo nosso). Estas questões evidenciam o que não quer calar: há preconceito (explícito ou velado) em relação ao professor voluntário.

Por sua vez, tratando-se da qualidade de vida, não restrita ao trabalho, a maioria absoluta dos professores voluntários aposentados (13) considera que houve uma substancial melhoria e os motivos alegados referem-se à flexibilidade de horário, à menor carga de trabalho, à satisfação pessoal e à saída das condições 'precárias' de trabalho da IES (2). A redução da carga de trabalho é enfatizada. Nesse aspecto, uma entrevistada esclarece: “[...] sim, minha qualidade de vida melhorou porque eu estava muito, mas muito sobrecarregada de trabalho e essa carga diminuiu agora para padrões 'mais normais'." (Ent. 10, CTC, grifo nosso). 
(14) Aposentei-me porque queria uma carga de trabalho menos estressante, até para desenvolver trabalhos de pesquisa com mais tempo e, talvez, melhores resultados. $\boldsymbol{A}$ sobrecarga de trabalho, enquanto na ativa, provocava-me muita tensão, era cansativa demais [...] (Ent. 3, CED, grifo nosso).

Estas colocações comparativas ao período em que estavam na ativa desvelam a realidade atual da universidade pública e a sobrecarga de trabalho a que são submetidos os docentes em prol de uma produtividade insana, tanto no ensino, quanto na pesquisa (SGUISSARDI e SILVA JR, 2009; BOSI, 2007; BIANCHET'TI, 2006).

Bianchetti (2006) refere-se a uma forma de 'produtivismo acadêmico' na qual as relações de trabalho são caracterizadas pela competição acirrada entre os pares e o individualismo. Todavia, a despeito de depoimentos favoráveis às conquistas em termos de qualidade no trabalho e qualidade de vida, identificamos a ocorrência de problemas relacionados às condições de trabalho para o desempenho de suas atividades regulares. Dos 20 professores, apenas sete deles dispõem de sala própria, quatro dividem-na com outros professores aposentados e outros quatro dividem-na com colegas da ativa. Os demais não informaram. No caso dos núcleos de pesquisa, dos 13 núcleos identificados, cinco deles não dispõem de instalações próprias. Há relatos de professores sobre situações constrangedoras, quando houve a solicitação para desocuparem as suas salas ou mesmo a ocupação das salas por outros professores ou núcleos de pesquisa, por vezes sem aviso prévio.

Conflitos como estes, relativos às condições de trabalho poderiam ser solucionados, caso houvesse uma Política de Pessoal especificamente dirigida ao trabalho voluntário, seja ele de natureza docente ou não. No entanto, 11 voluntários manifestaram que a política atual é satisfatória, consideram, dessa forma, a sua existência. Outros seis preferiram não emitir opinião e dois deles discordam de tal política. Analisando a questão, uma professora, pesquisadora emérita da IES, afirmou não existir uma política para o trabalho voluntário, pois o que existe são somente normas e regulamentos que devem ser seguidos. Outra entrevistada reforça esta avaliação:

(15) [...] as normas foram estabelecidas unicamente com o objetivo de 'regulamentar' a situação desses professores, porém não há estímulo à permanência, não há reconhecimento explícito da Instituição quanto à importância desse trabalho, não há preocupação com relação às condições em que as atividades estão sendo desenvolvidas [...] (Ent. 2, CED, grifo nosso). 
Analisando a questão, um professor, além de discordar de que exista uma "política de pessoal" na IES, destaca que o interesse no trabalho voluntário não é da instituição e, por isso, não há empenho com a formulação de uma "política"?

(16) Como professores voluntários precisamos atender a um certo número de atividades e isto não é uma política. Diria que os professores é que são os interessados em colaborar, ainda, com a UFSC. Não é a UFSC como instituição, que tem interesse no trabalho dos professores aposentados e como tal, ela não tem interesse em apresentar uma política de aproveitamento desses professores, na sua maioria, altamente qualificados [...] (Ent. 3, CED, grifo nosso).

Sem responder objetivamente sobre a questão da existência ou não de uma política de pessoal, emitiu a sua opinião de forma objetiva:

(17) Não tenho informações para generalizar a minha situação, mas tenho a opinião de que, se nos aposentamos, a UFSC não tem obrigação de nos aceitar como voluntários. Se não tiver um bom ambiente de trabalbo ou se estiver sendo discriminada, enfim, se não houver interesse do departamento no meu trabalho, vou fazer outras coisas [...] (Ent. 6, CFM).

\section{A POLÊMICA SOBRE A CONTRAPARTIDA FINANCEIRA}

Outra questão abordada e que se tornou polêmica refere-se a uma eventual contrapartida financeira da IES pelo trabalho docente voluntário, na qual se desvela a especificidade deste trabalho, no sentido de ser um "trabalho superqualificado prestado sem contrapartida financeira" e não um trabalho de responsabilidade social, ou mesmo inserido em propostas assistencialistas do tipo "amigo da escola". Nessa análise, emergem as diferentes concepções de trabalho, a natureza específica do trabalho docente, o sentido e o significado de ser professor e ser pesquisador durante décadas, enfim, a distinção percebida entre o trabalho docente de um professor/ pesquisador sênior e outras atividades voluntárias.

A maioria dos entrevistados (13) declarou-se favorável a algum tipo de contrapartida financeira, "para que o professor sinta-se mais estimulado a participar", elencando as seguintes possibilidades: a) uma bolsa de trabalho ou de pesquisa; b) ressarcimento das despesas decorrentes das atividades 
voluntárias; c) no caso de assessoria ou consultoria especializada em tarefas específicas.

Um professor sugere que possa ser até mesmo uma "contrapartida simbólica, afetiva, ou tributária”, e questiona de forma crítica:

(18) Quanto vale o trabalho de um professor com doutorado antigo; dezenas de artigos publicados; oito livros publicados, dos quais seis adotados em todos os cursos de graduação em Jornalismo do País; a experiência acadêmica e profissional de 35 anos e, [...] enfim, que ainda não entregou o boné? (Ent.14, CCE, grifo nosso).

(19) A comparação com outra universidade que oferece uma bolsa de pesquisa (UFPR) é enfatizada por uma entrevistada, que alega uma perda salarial crescente do professor aposentado, pois, "quem só se dedicou à pesquisa, ao ensino e à extensão (ou seja, não adicionou vantagens administrativas no salário) tem dificuldade hoje de se manter com o salário que recebe e tem muita incerteza quanto ao futuro." (Ent. 10, CTC).

Por outro lado, há uma forte preocupação com a legalidade ou não deste tipo de contrapartida financeira, evidenciada na fala a seguir, referindo-se especificamente, ao caso dos professores aposentados:

(20) [...] eu não sei em que categoria funcional um aposentado poderia ser enquadrado para ter contrapartida financeira em uma Universidade Federal. Eu gostaria de saber em que IES Federal isso acontece, e como se dá o processo. E quais são as obrigações. Talvez em algumas IES os aposentados recebam via Fundações, mas isso pode ser irregular. Enfim, se houver formas legais de se pagar um aposentado, não tenho nada contra [...] (Ent. 4, CFM).

As opiniões divergentes (contra qualquer forma de contrapartida financeira) ponderam determinadas questões relacionadas com a legalidade desse recebimento:

(21) Nós deveríamos ter salários decentes, TODOS. Sou favorável a lutarmos por paridade com os colegas da ativa, lutar por melhores salários para todos, por um plano de carreira adequado, por uma seguridade social decente, etc. Na atual situação, penso que receber uma complementação por trabalho voluntário seria injusto com os colegas da ativa [...] (Ent. 6, CFM, grifo nosso).

(22) A partir do momento que este serviço é voluntário não deveria ter remuneração financeira [...] (Ent. 13, CCS). 
(23) Se for voluntário, não deve ter remuneração. Porém deve se ter uma politica de concursos para substitutos ou adjuntos se há uma necessidade para Universidade de corpo docente, o programa de voluntário não deve servir como improvisação [...] (Ent. 16, CCS, grifo nosso).

\section{REFLEXÕES FINAIS}

A questão do voluntariado em Instituições de Ensino Superior suscita muitas reflexões, por tratar-se de um tema polêmico que coloca em xeque convicções pessoais, coletivas e políticas sobre a natureza do trabalho, como categoria central na existência humana, especificamente no caso de um trabalhador intelectual, o docente universitário de uma instituição de ensino superior pública. Neste caso, a questão assume contornos muito específicos, considerando-se os aspectos legais, éticos e morais envolvidos.

Legalmente, a exigência de concurso público é um dos fatores limitadores para a docência voluntária nessas instituições públicas, mas há que se considerar outros impedimentos de ordem jurídico-legal e institucional e a posição assumida pelo movimento sindical docente que, gradativamente, se posiciona sobre esta questão polêmica.

Neste artigo, destacamos as reflexões de um grupo de 20 docentes voluntários de uma IES acerca da vivência do trabalho voluntário, as suas motivações, as condições de trabalho, as relações de trabalho, bem como a legislação interna que regulamenta o trabalho voluntário na IES (Resolução 012/99).

A etapa da pesquisa descrita nesse texto propicia uma compreensão dos motivos que influenciam o docente de uma universidade pública a dar continuidade ao trabalho desenvolvido por três ou mais décadas (no ensino, pesquisa e extensão), de forma voluntária, sem qualquer tipo de remuneração ou contrapartida financeira, cumprindo um plano de trabalho previamente estabelecido e aprovado por diversas instâncias organizacionais, sob a tutela de um "supervisor". No caso dos professores não aposentados (a minoria), jovens recém-doutores, observamos que a opção advém da espera de abertura de concurso público em suas respectivas áreas de atuação.

Nesse aspecto específico, surge uma questão de fundo a ser investigada mais profundamente: a identificação e a vocação pelo ofício de ensinar, formar e construir o conhecimento, conforme ressalta Macedo 
Loureiro no posfácio da obra "Docentes universitários aposentados: ativos ou inativos?" (VEIGA, 2006), é um fator motivacional mais influente do que a centralidade que o trabalho ocupa na vida desses docentes?

Outro fator que aflora nos depoimentos dos professores voluntários aposentados como um dos aspectos motivacionais é a fuga das condições precárias de trabalho na universidade, sob a égide de um 'produtivismo insano', no qual predominam práticas utilitárias, individualistas e competitivas (LEDA, 2006). A propalada melhoria na qualidade de vida e na qualidade do trabalho é destacada, em função de uma situação anterior muitas vezes insustentável com sérias implicações na saúde física, emocional e mental do docente.

O estudo revela, também, que o desconhecimento de alguns aspectos da legislação - interna e federal - dificulta, sobremaneira, o reconhecimento de direitos fundamentais ao exercício do trabalho voluntário em condições dignas, como é o caso do ressarcimento das despesas efetuadas no desempenho das atividades cotidianas.

Constatamos, ainda, que, embora em um primeiro momento, os docentes voluntários tenham sugerido a existência de um clima favorável de aceitação, de bom relacionamento pessoal e de trabalho, os depoimentos que se sucederam evidenciam uma contradição no tocante ao "acolhimento", à respeitabilidade e ao amparo profissional que este contingente de profissionais altamente qualificados é merecedor. Não se trata de um problema nas relações pessoais, mas sim nas relações institucionais, nas quais observamos um desrespeito generalizado, tanto no que diz respeito à regulamentação interna, com exigências absurdas, como é o caso da obrigatoriedade de um supervisor e da coorientação de trabalhos terminais de cursos de graduação e pós-graduação, como também das condições de trabalho disponibilizadas pela instituição. A externalização da falta de reconhecimento da instituição aparece em diversas falas de professores aposentados, como a pergunta lançada em tom veemente: "alguém vai perguntar: escuta aqui quem é você?"

Esse e outros depoimentos de teor denunciativo e crítico apontam para uma situação caótica, em que se desvela a precarização do trabalho docente voluntário, categoria ampla, aqui considerada não apenas restrita à esfera econômica, como alerta Bosi (2007) mas que se expressa também nas relações sociais de trabalho, nas condições sob as quais o trabalho voluntário é desenvolvido e nas demais implicações de natureza política e social. A 
esta amplitude de acepção da categoria precarização, acrescentamos a esfera da subjetividade do trabalho, do sentido e do significado que este assume na vida pessoal do ser humano professor.

A pesquisa não se encerra aqui e estamos dando continuidade aos estudos, apresentando propostas objetivas de encaminhamento da questão aos órgãos diretivos da instituição em tela, a partir de estudos comparados em outras instituições públicas de ensino superior. Reconhecemos que, nessa etapa da pesquisa, foram desveladas algumas situações que necessitam melhor esclarecimento e aprofundamento. 


\section{REFERÊNCIAS}

ALVES, G. Trabalho e globalização. Revista Autor, v. 4, n. 38, ago. 2005.

BIANCHET'TI, L. Política de Avaliação e Acompanhamento da CAPES: Ingerências e Impactos nos PPGES. Atos de Pesquisa em Educação, Blumenau, v. 1, n. 2, p.140-153, ago. 2006. Disponível em: <http://proxy.furb.br/ojs/index.php/atosdepesquisa/article/ view/36/12>. Acesso em: 16 nov. 2010.

BOSI, A. P. A precarização do trabalho docente nas instituições de ensino superior do Brasil nesses últimos 25 anos. Educação e Sociedade, São Paulo, v. 28, n. 101, p. 1503-1523, set./dez. 2007.

BRASIL. Lei no 9.608 de 18, de fevereiro de 1998. Dispõe sobre o serviço voluntário e dá outras providências. Diário Oficial da República Federativa do Brasil, Brasília, DF, 19 fev. 1998. Disponível em: <http://www.planalto.gov.br/ccivil_03/Leis/L9608.htm>. Acesso em: 16 nov. 2010.

CATTANI, A. A outra economia. Porto Alegre: Veraz, 2003.

DAL ROSSO, S. "Orelhas secas": condições de trabalho de contratados pelo serviço público. Universidade e Sociedade, Brasília, v. 10, n. 23, p. 141-152, fev. 2001. Disponível em: <http://www.revistaautor.com.br/artigos/2004/38gal.htm>. Acesso em: 13 dez. 2005. INÁCIO, A.; WAGNER, J. L. A aposentadoria do professor que trabalhou em condições insalubres sob o regime da CLT. Universidade e Sociedade, Brasília, v. 13, n. 30, p. 45-47, jun. 2003.

LEDA, D. B. Trabalho docente no ensino superior sob o contexto das relações sociais capitalistas. In: REUNIÃO ANUAL DA ASSOCIAÇÃO NACIONAL DE PÓS-GRADUAÇÃO E PESQUISA EM EDUCAÇÃO - ANPED, 29., 2006, Caxambu. Anais... Caxambu: ANPED, 2006.

MANCEBO, D.; GOULART, S.; DIAS, V. C. Trabalho Docente na UERJ (1995-2008): Intensificação, Precarização e Efeitos de Subjetivação. In: SEMINÁRIO INTERNACIONAL DA REDE DE PESQUISADORES SOBRE ASSOCIATIVISMO E SINDICALISMO DOS TRABALHADORES EM EDUCAÇÃO, 2010, Rio de Janeiro. Anais... Associação e Sindicatos de Trabalhadores em Educação, 2010. p. 1-16.

OLIVEIRA, G. Trabalho flexibilizado na universidade. Universidade e Sociedade, Brasília, DF, v. 6, n. 11, p. 48-56, jun. 1996.

PINTO, J. B. M.; GUEDES, M. A.; BARROS, V. A. O trabalho voluntário, solidariedade e política: um estudo com os agentes da pastoral Carcerária de Belo Horizonte. In: PIMENTA, M. L.; SARAIVA, L. A. S.; CORRÊEA, M. L. Terceiro Setor dilemas e polêmicas. São Paulo: Saraiva, 2006.

PINTO, M. B. A subordinação do trabalho docente à lógica do capital. Revista Outubro, São Paulo, n. 4, p. 17-24, 2000.

PINTO, M. B. Precarização do trabalho docente: a educação como espaço de acumulação do capital. Universidade e Sociedade, Brasília, v. 11, n. 27, p. 55-61, jun. 2002.

RAMPINELLI, G.; GUIMARÃES, V. N. Responsabilidade social corporativa: desvelando intencionalidades não reveladas. In: PIMENTA, M. L.; SARAIVA, L. A. S.; CORRÊA, M. L. Terceiro Setor: dilemas e polêmicas. São Paulo: Saraiva, 2006. 
SGUISSARDI, V.; SILVA JÚNIOR, J. R. Trabalho Intensificado nas Federais: pós-graduação e produtivismo acadêmico. São Paulo: Xamã, 2009.

SILVA, E. P.; SILVA JÚNIOR, J. R. Estranhamento e Desumanização nas Relações de Trabalho na Instituição Universitária Pública. Revista HISTEDBR On-line, Campinas, p. 223-238, ago. 2010. Número especial. Disponível em: <http://www.histedbr.fae.unicamp. br/revista/edicoes/38e/art14_38e.pdf>. Acesso em: 01 nov. 2010.

SINGER, P. Economia Solidária. In: CATTANI, A. A outra economia. Porto Alegre: Veraz, 2003.

TEODÓSIO, A. S.; PENA, R. P.; VENEROSO, R. S. Nada de novo no front: caminhos e descaminhos do voluntariado e do capital social como formas de ativismo comunitário. In: PIMENTA, M. L.; SARAIVA, L. A. S.; CORRÊA, M. L. Terceiro Setor: dilemas e polêmicas. São Paulo: Saraiva, 2006.

UNIVERSIDADE FEDERAL DE SANTA CATARINA. Pró-Reitoria de Graduação. Resolução no 012/CUn/99, de 27 de julho de 1999. Dispõe sobre o Programa de Serviço Voluntário, que disciplina a participação de profissionais em atividades de ensino, pesquisa e extensão na UFSC. Florianópolis: CUn, 1999. Disponível em: <http://www.reitoria.ufsc.br/estagio/ legislacao/res\%2012\%20cun\%209927.doc>. Acesso em: 16 nov. 2010.

VEIGA, I. P. A (Coord.). Docentes universitários aposentados: ativos ou inativos? Araraquara: Junqueira\&Marin, 2007.

VERGARA, S. Métodos de pesquisa em administração. São Paulo: Atlas, 2002.

\section{NOTAS}

${ }^{1}$ Um dos raros estudos investigativos culminou com a publicação do livro: "Docentes Universitários Aposentados: ativos ou inativos (2007). A pesquisa realizada na Universidade de Brasília (UNB) foi coordenada pela professora Ilma Passos Alencastro da Veiga. O foco de interesse, nesse caso, é a trajetória profissional e pessoal do docente.

${ }^{2}$ Entendemos que a precarização do trabalho docente envolve diferentes aspectos, como a deteriorização das relações de trabalho com a ampliação da desregulamentação e perdas de garantias legais, historicamente conquistadas pela classe trabalhadora; a desqualificação profissional dos docentes; a intensificação do trabalho, bem como a degradação das condições de trabalho (condições materiais, financeiras, psicossociais). Observa-se que a intensificação do trabalho é uma das facetas mais visíveis da precarização, materializada pela ampliação da jornada de trabalho dos docentes, a inclusão de novas demandas e atribuições (no ensino, pesquisa e extensão) decorrentes das políticas educacionais e da exigência de uma crescente produtividade nas Instituições de Ensino Superior.

3 Profissionalização entendida como uma busca de formação e capacitação dos voluntários para o desempenho das atividades a que se propõem, muitas delas de caráter técnico e administrativo. Nas ONG’s essa profissionalização é um fenômeno visivelmente observável. 
4 Surpreendeu-nos encontrar professores não-aposentados e muito jovens (com idade média de 34 anos) no trabalho docente voluntário. Dois destes professores atuam no Centro de Ciências da Saúde e esclareceram a sua intenção: a possibilidade de ser docente na graduação sem estar concursado como professor da instituição, já que não há abertura de vagas nas suas respectivas áreas.

5 A partir de março de 2012, em decorrência das avaliações e propostas de alteração, ou mesmo revogação da Resolução 12/CUn/99 (uma dessas propostas foi apresentada pelos pesquisadores, autores desse artigo) está sendo discutida nos órgãos ..????. uma nova Resolução que substituirá a atual.

${ }^{6}$ Esses convites evidenciam o interesse institucional pela manutenção de professores/ pesquisadores mesmo após a sua aposentadoria ou, no caso de professores não aposentados, pela carência de profissionais e /ou pesquisadores em determinados campos de conhecimento.

${ }^{7}$ O que é discutível, pois há, sim, interesse da instituição, quando se trata da produção científica destes professores aposentados doutores e pesquisadores, muitos deles liderando grupos de pesquisa bastante prestigiados na Academia.

Recebido: 03/12/2010 